\title{
THE CELL FOR ELECTRON IRRADIATION OF STRESSED STEEL SAMPLES IN A SUPERCRITICAL WATER FLOW FOR CORROSION EVALUATION
}

\author{
A.S. Bakai, V.N. Boriskin, M.I. Bratchenko, R.N. Dronov, \\ S. V. Dyuldya, Yu.V. Gorenko, S. V. Shelepko \\ National Science Center "Kharkov Institute of Physics and Technology", Kharkiv, Ukraine \\ E-mail: romandronov@kipt.kharkov.ua
}

To study experimentally the stress enhanced corrosion of structural materials in a water coolant flow under electron irradiation, a novel design of the target irradiation cell was developed. The stress application scheme is described and the stress-strain state of samples is calculated. Hydraulic resistance of the stainless steel 12X18H10T samples loaded cell has been measured at a dedicated facility and is discussed in terms of hydraulic and hydrodynamic models. System Thermal Hydraulics calculations have shown the device capability to operate efficiently in a natural convection driven Supercritical Water Circulation Loop.

PACS: 07.35.+k;29.20.Ej;28.52.Fa;81.70.-q;61.82.-d;47.85.Dh

\section{INTRODUCTION}

Investigation of the role of irradiation on the corrosion resistance of structural alloys is of vital importance for selection of the Generation IV Supercritical WaterCooled Reactor (SCWR) materials [1]. Gamma heating under SCWR conditions, which induces enhancement of radiolysis and corrosion kinetics at interfaces, can be efficiently simulated by electron beam (EB) irradiation over a wide range of deposited dose and temperature.

Currently, the RDE "Accelerator" of NSC KIPT sited LEA-10 linac [2] based Electron Irradiation Test Facility (E.I.T.F.) still remains the only operating unit capable of in situ irradiation of samples in a supercritical water (SCW) circulation loop (SCWCL, Fig. 1) at a $50 \ldots 80 \mathrm{gm} / \mathrm{s}$ coolant mass flow rate $[3,4]$.

The facility has been operating since 2012 when a pilot 497-h-long $\left(e^{-}, \gamma\right)$-irradiation of $\mathrm{Zr}-1 \% \mathrm{Nb}$ - and NiCr-based candidate alloys by a $9.76 \mathrm{MeV} / 6.23 \mathrm{~kW}_{\mathrm{e}}$ scanning EB in the vicinity of the water coolant pseudocritical point $T_{\mathrm{pc}}(P)=379.5^{\circ} \mathrm{C}$ at $23.5 \mathrm{MPa}$ coolant pressure $P$ was successfully completed [3] by virtue of the developed unique methodology and instrumentation $[3,5$ - 7]. Post-irradiation studies of irradiated coupons [4] revealed drastic enhancement of their oxidation/corrosion rate due to the Irradiation Assisted Corrosion (IAC) [1] effects. Besides, the Irradiation Assisted Stress Corrosion Cracking (IASCC) [1] damage was found in the austenitic stainless steel (SS) 12X18H10T piping of the target irradiation cell [4]. It was recently attributed [8] to the impact of the EB induced thermalelastic hoop stress which initiated the observed severe inter-granular cracking, exfoliation and delamination.

The influence of mechanical stress on the corrosion behavior of materials is regarded [1] as a root driving force of their accidental fracture loss of performance. Stress affected corrosion and SCC under irradiation deserve dedicated experimental studies. This is just the roadmap of our current $R \& D$. The goal of this paper is to present the developed design solutions concerning the novel target Irradiation Cell (IC) assembly which first grants us a capability to perform irradiation experiments in situ SCW with coupons under controlled stress load.

A brief review of the E.I.T.F. SCWCL setup (Sec. 1) is followed by the description of the modernized IC (Sec. 2) and evaluation of its performance (Secs. 3,4) in the irradiation experiments planned for near future.

\section{E.I.T.F. CIRCULATION LOOP BASICS}

After modernization, the SCWCL version "Loop1b" keeps all major features of the prior "Loopla" stand design approved at successful long-term operation with near-critical coolant flow under irradiation [3].
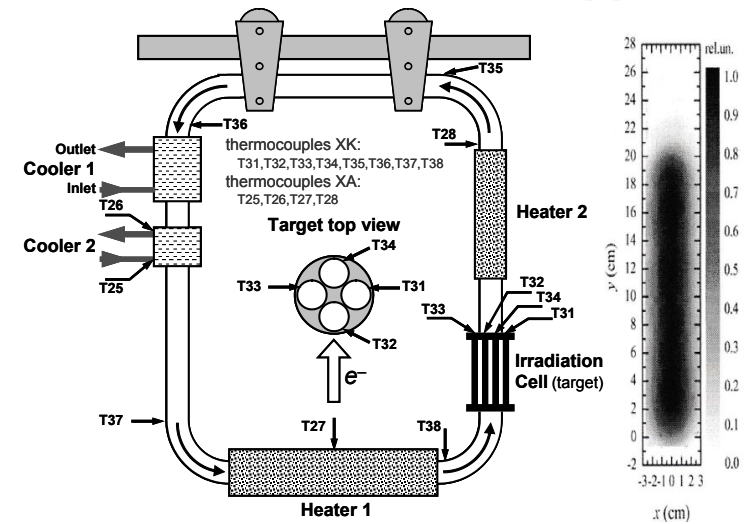

Fig. 1. Supercritical Water Circulation Loop "Loop1b" layout and the glass plate measured spatial distribution of scanning e-beam in front of the irradiation cell

The dimensions of the rectangular loop (see Fig. 1) are $1.5 \times 1.2 \times 0.5 \mathrm{~m}$ and they enable its mounting in the linac shelter. It is made of the $4 \ldots 6 \mathrm{~mm}$ thick SS $12 \mathrm{X} 18 \mathrm{H} 10 \mathrm{~T}$ pipe of inner $\varnothing 32$. The loop inner volume is $\approx 4$ liters.

The coolant circulates due to natural convection driving forces governed by its temperature $T$ and density $\rho$ differences at the vertical levels of installed heaters and coolers. When the e-beam is off, the power $\left(1 \ldots 4 \mathrm{~kW}_{\text {th }}\right)$ of the main electric Heater 1 heats water and put it in motion due to the increase in buoyancy. Coolers 1 and 2 take this power away. This results in a steady state circulation, the supplementary vertical Heater 2 is used only to control its start-up direction. When the beam is on, the vertically mounted target cell absorbs the EB power and serves as a powerful $\left(2 \ldots 7 \mathrm{~kW}_{\text {th }}\right)$ heater, too.

The heart of the facility is the irradiation cell. Its developed, tested and approved [3 - 5] design (Fig. 2) is a compromise solution which balances the capabilities to hold massive samples, to deliver EB energy to them, and to possess enough mechanical strength under high internal pressure and thermal-elastic loads. 


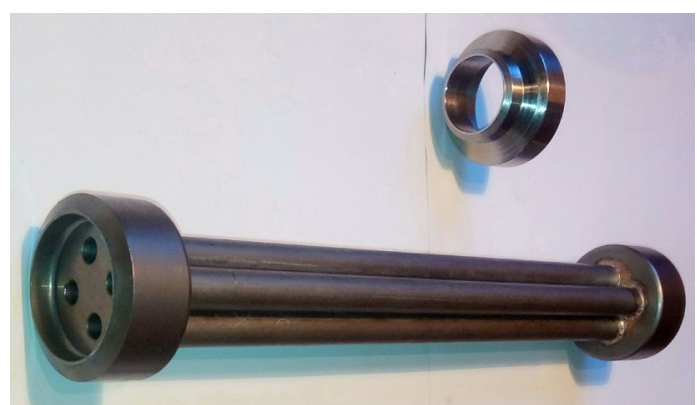

Fig. 2. Irradiation cell with flanges and mating appliance before its welding into the SCWCL assembly

The IC consists of four parallel channels. Each of them is a $28 \mathrm{~cm}$ long $2 \mathrm{~mm}$ thick $\varnothing 10$ round tube made of the same material, SS $12 \mathrm{X} 18 \mathrm{H} 10 \mathrm{~T}$, as the main loop piping the IC is welded with before irradiation. This prohibits the design relevant electrochemical corrosion.

The IC longitudinal and transversal dimensions fit the parameters of the linac EB scanning system (a horn) which covers, fairly evenly, an area of $(210 \times 45) \mathrm{mm}^{2}$ (see the glass photometry map in Fig. 1). The IC is $7 \mathrm{~cm}$ longer and its top placed samples are only weakly $\gamma$-irradiated. This feature (along with the reduced impact on the samples in the IC rear tube) allows to incorporate reference "witness" specimens into the irradiation plan and obtain of different absorbed dose rates and temperatures within the same experiment. Such fine tuning is well described using the computational dosimetry approach and gives valuable information for postirradiation analysis of corrosion phenomena $[3,4,8]$.

\section{A CONTROLLABLY STRAINED SAMPLES HOLDING CASSETTE}

In our earlier experiments [3 - 8], no stress was intentionally applied to the IC piping and internals though the thermal-elastic stress present due to temperature unevenness of the EB induced heating. However, the thermal-elastic effects are hard to control. Hence, the task was set to develop a simple but reliable design of sample holders which allows to predict and to maintain the stress-strain state of each of the irradiated samples. The R\&D outputs were implemented in the novel device of the samples holding cassette shown in Fig 3.

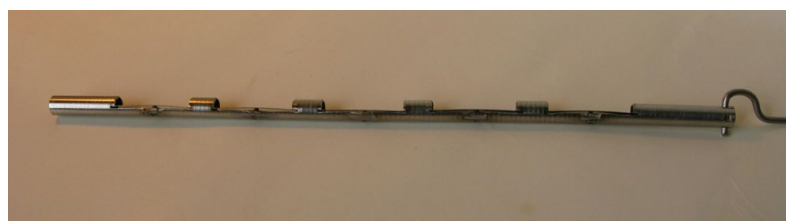

Fig. 3. The novel cassette holding five bent samples

A prototype solution, obviously, with no concern of high-pressure high-temperature specificity of SCW relevant irradiations, was found in extensive technical literature on the vital problem of monitoring SCC of trunk pipelines [9] and industrial (BPI-2 type) corrosion rate sensors for civil engineering. The suggestion was to apply the simplest scheme of the mid-span concentrated load of a freely supported beam, or thin plate, which is well covered by the shell elasticity handbooks [10].

We plan irradiations of thin $(0.3 \mathrm{~mm})$ rectangular $(40 \times 9.7 \mathrm{~mm}) \mathrm{SS} 12 \mathrm{X} 18 \mathrm{H} 10 \mathrm{~T}$ made specimens shown in Fig. 4. The adopted loading scheme is drafted in Fig. 5.
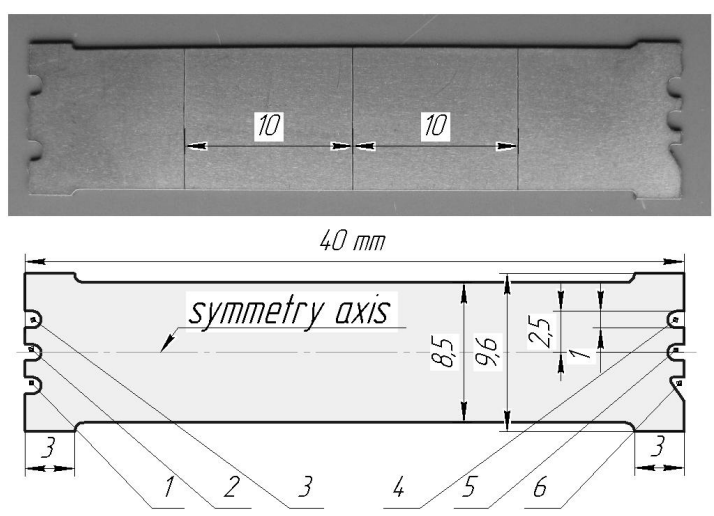

Fig. 4. Frontal view of a sample tagged with edge snicks 1-6 for the specimen binary encoding

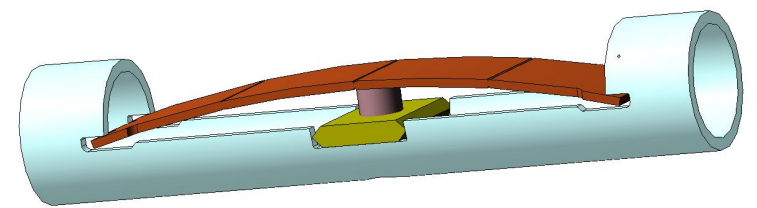

Fig. 5. The unit of a cassette with a specimen freely edge-supported on the holder notches and with the bend adjusting screw applied to the sample mid-span

For such a scheme, elementary considerations of static elasticity lead to a simple linear ratio of the maximal deflection $d$ of the thin plate midpoint $x=0$ and this point raised maximal tensile stress $\sigma_{\max }$ :

$$
d=\frac{\sigma_{\max } \cdot l_{\mathrm{eff}}^{2}}{6 \cdot E \cdot h} \leftrightarrow \sigma_{\max }=6 \cdot E \cdot\left(\frac{h}{l_{\mathrm{eff}}}\right) \cdot\left(\frac{d}{l_{\mathrm{eff}}}\right),
$$

where $h$ is the sample thickness, $l_{\text {eff }}$ is its effective length (the distance between points of leaning), $E$ is the Young modulus of material elasticity. The stress distribution along $x$ axis is symmetric and triangular:

$$
\sigma(x)=\sigma_{\max } \cdot\left(1-2|x| / l_{\text {eff }}\right) .
$$

It is depicted in Fig. 6 where thin lines are calculated according to Eqs. (1), (2) and the thick ones represent the results of the validation Finite Element Method (FEM) computer simulation of the elastic stress-strain state by means of the freely distributed code FreeFEM++ [11].

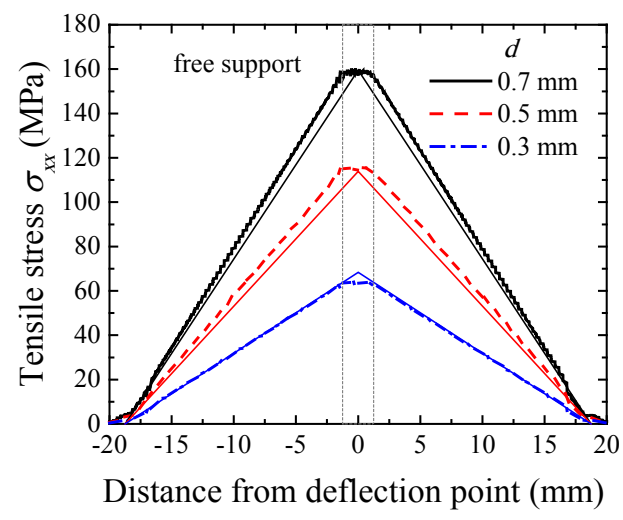

Fig. 6. Spatial distributions of tensile stress $\sigma_{x x}$ on the convex surface of a specimen free supported in the cassette for its different maximal deflections $d$

Calculations have shown that in order to guarantee the sample deformation within the elasticity domain (for the SS $12 \mathrm{X} 18 \mathrm{H} 10 \mathrm{~T}$ this is limited by the temperature 
reduced yield stress, $\sigma_{0.2}=174 \mathrm{MPa}$ at $T=400^{\circ} \mathrm{C}$ ), deflections $d$ must not exceed $0.7 \ldots 0.8 \mathrm{~mm}$. It is worth noting that the necessary condition of this loading scheme adequacy is the free leaning of the sample edges on the holder notches. If violated, FEM calculation shows strong stress concentration near the edges and complex perturbations of the stress picture of Fig. 6 . These effects have to be avoided with precise careful mounting of samples into cassettes.

However, the impact of stress concentration on corrosion cracking is also of special interest. We impose it during samples preparation using the precisely controlled scratching. For each of 20 samples, six $\sim 80 \mu \mathrm{m}$ wide $\sim 10 \mu \mathrm{m}$ deep scratches ( 3 per each side) were plotted with a diamond cutter as shown in Figs. 4, 5. Their geometry, incl. shoulders, was routinely characterized by means of optical metallography instrumentation and served as input for FEM calculations (Fig. 7).

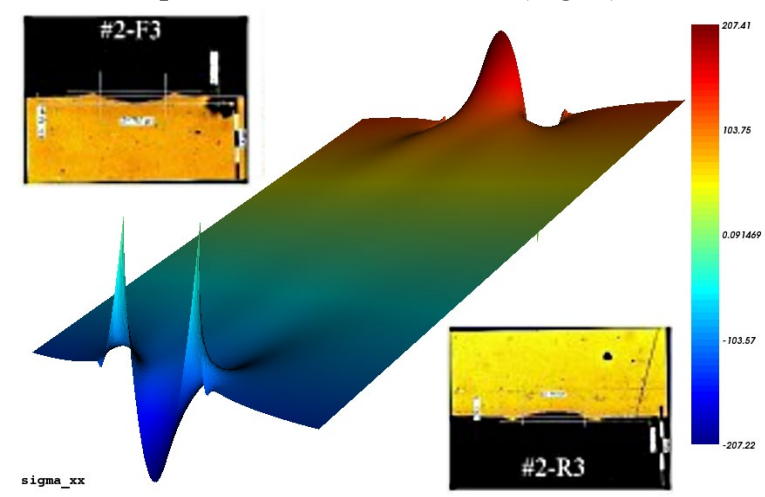

Fig. 7. Tensile stress field in the vicinity of scratches on both sides of the sample. 2D FEM calculation

One can see that tensile (at the convex side) and compressive (at the concave side) stress is concentrated at the scratch bottom as well as near its shoulders. The scratch acts as a local amplifier of the slow varying base stress (2). FEM calculations (Fig. 8) predict amplification factors of about $1.5 \ldots 1.7$. In the vicinity of scratches, the enhanced stress is free to exceed elastic limits and/or to initiate stress corrosion cracking and fracture.

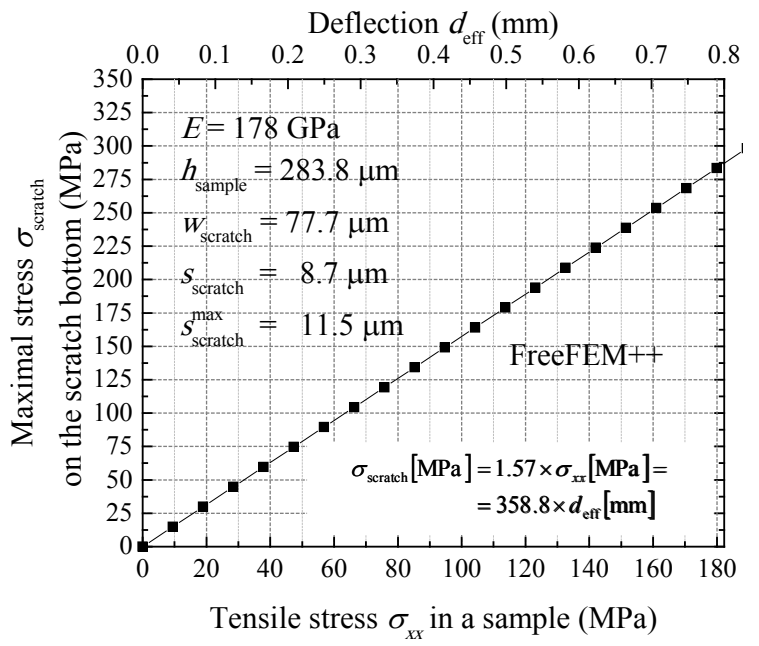

Fig. 8. Stress concentration diagram in a typical scratch evaluated from FEM stress calculations

Having fixed the adopted novel design of the irradiation cell, we proceeded to the evaluation of the IC performance in the SCWCL at experimental conditions.

\section{THE IRRADIATION CELL HYDRAULIC RESISTANCE MEASUREMENTS}

The designed IC is specifically intended for use in a circulation loop with natural convection of near-critical water. The steady-state circulation regime is established when the pressure drop $\Delta P$ over the closed loop vanishes, $\Delta P=0$. In the case of planned irradiations in the vicinity of the water coolant super-critical transition, the instantaneous pressure drop depends nonlinearly on the circulating coolant thermodynamic (the externally applied pressure $P \geq P_{\mathrm{c}}$, temperature $T \approx T_{\mathrm{pc}}$ and the Equation of State, EOS, determined density $\rho(P, T)[12])$ as well as kinetic (the dynamical, $\eta$, and kinematical, $v=\eta / \rho$, viscosity) parameters. Generally, the overall $\Delta P$ consists of the differences in hydrostatic pressure $\rho \cdot g \cdot h$ ( $g$ is the acceleration of gravity, $h$ is the appropriately defined elevation level) and in dynamical speed head $\rho v^{2} / 2$ ( $v$ is the hydraulic section $S_{\mathrm{H}}$ and diameter $D_{\mathrm{H}}$ dependent linear velocity of a water fluid) but also incorporates the dissipative pressure loss $\Delta P_{\text {loss. }}$ The evaluation of the latter one is the most obstructive and design sensitive task of the hydraulic systems analysis.

The distributed frictional part of $\Delta P_{\text {loss }}$ depends on the fluent turbulence degree qualifier, the Reynolds number $\operatorname{Re}=v D_{\mathrm{H}} / v=\rho \cdot v D_{\mathrm{H}} / \eta$. It is well estimated in simple cases, e.g., of flows in straight long polished tubes of round section. However, in actual piping, the evaluation of $\Delta P_{\text {loss }}$ is complicated by local perturbations of the fluent speed distribution and energy dissipation. Thus the hydraulic resistance of a device is strongly affected by the details of its geometry and materials, esp. for devices with complex internals. Evidently, this is just the case of the designed IC.

To predict the natural circulation mass-flow rate $W$ under the expected conditions from the steady-state System Thermal Hydraulics (STH) equation $\Delta P(W)=0$, it is imperative to evaluate the dependence of the IC relevant pressure loss $\Delta P_{\mathrm{IC}}(W)$ on the parameters of the water flowing through it. However, the design of IC (see Figs. 2, 3) is rather complex hydrodynamically. Needless to say, $\Delta P_{\mathrm{IC}}$ cannot be evaluated accurately enough based on the regular hydraulics handbooks [13] formulae and data. Advanced computer modeling and/or dedicated experimental measurements are required.

We applied these both techniques to plan future experiments. The quantity of interest, $\Delta P_{\mathrm{IC}}$, can be equally described by the irradiation cell Hydraulic Resistance Coefficient (HRC), $\zeta_{\text {IC }}$. By definition,

$$
\Delta P_{\mathrm{IC}}=\zeta_{\mathrm{IC}} \cdot \frac{\rho \cdot v_{\text {inlet }}^{2}}{2},
$$

where $v_{\text {inlet }}$ is the characteristic coolant speed at the IC inlet. Coupled with the coolant density $\rho$, this presents the normalization factor required to define the nondimensional dissipative factor $\zeta_{\mathrm{IC}} \geq 0$.

Direct measurements of $\Delta P_{\mathrm{IC}}$ (and $\zeta_{\mathrm{IC}}$ ) are generally feasible by means of appropriate (and thus rather expensive) flow meters and pressure-gauge instrumentation. However, such a straightforward technique looked too complicated in our case because of the high-pressure $(P>23 \mathrm{MPa})$ high-temperature $\left(T \sim 350 \ldots 400^{\circ} \mathrm{C}\right)$ nature of far-sub- and super-critical circulation experi- 
ments as well as due to the expected diversity of the IC internals, (cassettes and coupons) and the e-irradiation deposited power essential impact on circulation dynamics. Besides, the facility qualification method has to be massive and non-destructive. However, the welded joint technique of the IC fitting into the "Loop1b" SCWCL piping impedes conducting multiple experiments with the same IC specifically loaded with samples. Consequently, such a qualification measurement of $\zeta_{\text {IC }}$ costs as much and lasts as long as the planned experiment itself.

To overcome these obstacles in a short period of time, we suggested an indirect but much more simple technique. It aggregates the classic-scheme experimental measurements of $\zeta_{\mathrm{IC}}$ for water at normal (atmospheric) pressure and conventional pre-boiling $\left(T<100^{\circ} \mathrm{C}\right)$ temperatures with the theoretical modeling framework of their extrapolation to the near-critical domain based on the known thermo- and hydrodynamic correlations.

\subsection{HYDRAULIC RESISTANCE EVALUATION METHOD AND EXPERIMENTAL FACILITY}

The proposed technique is based on measuring the duration of free, gravity caused outflow of water from a reservoir (a tank) having a large open surface through the examined vertical outlet segment of a comparatively much smaller hydraulic section. In such a system, the outflow expiration time depends on the pressure loss in the outlet unit of the pipeline, incl. both local losses on its constituents and the segment length spread friction loss. The searched HRC of the outlet pipeline is derived from differential measurements of the given volumetric capacity tank drainage timeline for different outlet options, particularly, with and without the IC, or with the ICs having different internal loadings.

This idea was embodied in the experimental facility shown, with constitutive dimensions, in Fig. 9. The cylindrical tank of $S_{\text {ank }}=334 \mathrm{~cm}^{2}$ open surface area is linked to the $\approx 10 \mathrm{~cm}$ long steel round tube segment of the "Loop1b" main piping with the diameter $D=32 \mathrm{~mm}$. The rest of the pipeline consists of the exchangeable IC under investigation and the ball valve of the same effective hydraulic diameter and the same hydraulic section $S_{\text {out }}=S_{\text {n }}$ $=S=\pi D^{2} / 4=8 \mathrm{~cm}^{2}$ as the input section.

For such a facility, an ansatz of the hydraulic resistance evaluation method establishment follows from the elementary considerations of the incompressible liquid hydromechanics [13]. First assuming constant temperature and enthalpy of the experiment and neglecting compressibility ( $\rho=$ const) and buoyancy at negligible external and internal heating of a fluid (the kinetic energy dissipation is small), from the mass conservation law we deduce that (i) the fluent velocity $V$ is constant on each segment of the outlet pipeline and (ii) it is reciprocally proportional to their hydraulic sections $S$.

$$
v_{\text {tank }} \cdot S_{\text {tank }}=v_{\text {in }} \cdot S_{\text {in }}=v_{\text {IC }} \cdot S_{\text {IC }}=v_{\text {out }} \cdot S_{\text {out }}=Q \text {, }
$$

where $v_{i}$ and $S_{i}$ are indicated in Fig. 8 and $Q=\mathrm{d} V / \mathrm{d} t$ is the measurable volumetric flow rate of a tank discharge.

Next, let us count out the water column elevation $h$ from the outlet valve bottom level and address to the Bernoulli law based equation:

$$
\rho \cdot g \cdot h+P(h)+\frac{\rho \cdot v_{\text {tank }}^{2}}{2}=P(0)+\frac{\rho \cdot v_{\text {out }}^{2}}{2}+\Delta P_{\text {loss }}
$$

In our case, pressure $P(h)=P(0)=P_{\text {atm }}$.

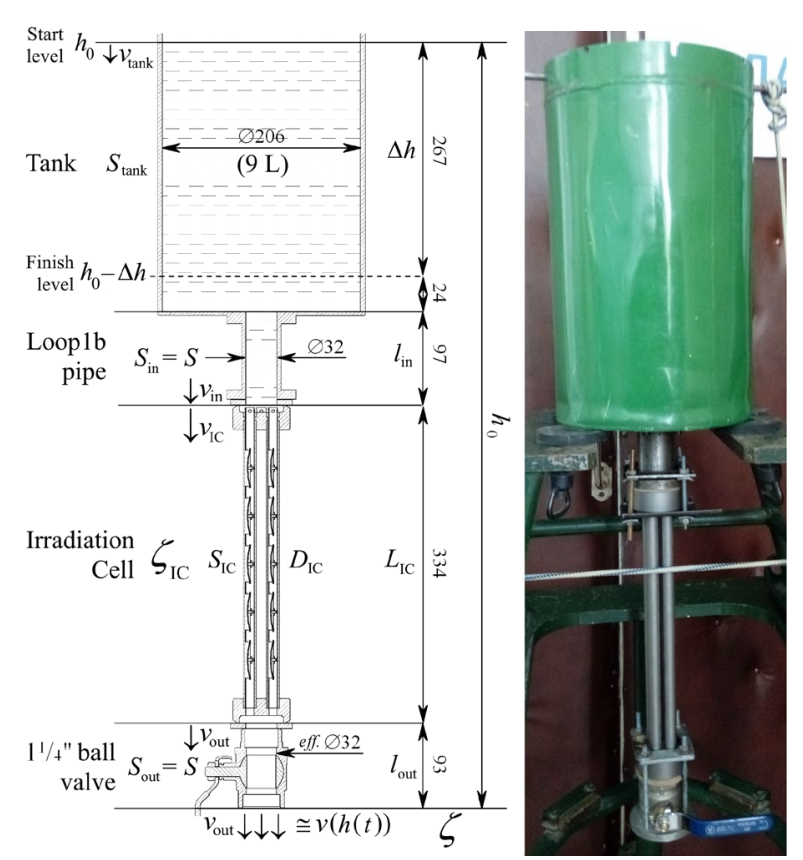

Fig. 9. The draft and general view of the experimental facility for the IC hydraulic resistance measurements

Let us define the facility pipeline total HRC $\zeta$ as $\Delta P_{\text {loss }}=\zeta \cdot \rho v_{\text {in }}^{2} / 2$, and recall the $v_{\text {tank }}=v_{\text {in }} \cdot\left(S_{\text {in }} / S_{\text {tank }}\right)$ and $v_{\text {in }}=v_{\text {out }} \cdot\left(S_{\text {out }} / S_{\text {in }}\right)$ ratios of Eq. (4). By resolving (5), we readily obtain the generalized Torricelli formula

$$
v_{\text {out }}(h)=\sqrt{\frac{2 g h}{1+\left(\zeta-\left(\frac{S_{\text {in }}}{S_{\text {tank }}}\right)^{2}\right) \cdot\left(\frac{S_{\text {out }}}{S_{\text {in }}}\right)^{2}}} \cong \sqrt{\frac{2 g h}{1+\zeta}} .
$$

Here we neglect the term $\left(S_{\text {out }} / S_{\text {tank }}\right)^{2} \sim 6 \cdot 10^{-4}<<1$ (this is valid except for the irrelevant case of extremely small $\zeta<<1$ ) and recall that $S_{\text {in }}=S_{\text {out }}=S$, the hydraulic section of the main piping of the SCWCL and our facility.

The tank discharge timeline $t(h)$ follows from the mass conservation law (4) based continuity equation of the time $t$ dependent but spatially uniform flux $Q(h(t))$ :

$$
\mathrm{d} V=S_{\text {tank }} \mathrm{d} h=Q(h) \mathrm{d} t \equiv v_{\text {out }}(h) \cdot S_{\text {out }} \mathrm{d} t,
$$

where $\mathrm{d} V$ is the instantaneously discharged volume and $v_{\text {out }}(h)$ is determined by Eq. (6). By solving this first-order ordinary differential equation $\mathrm{d} h / \mathrm{d} t=\left(S_{\text {tank }} / S_{\text {out }}\right) \cdot v_{\text {out }}(h)$ with initial condition $h(0)=h_{0}$, one obtains

$$
\begin{aligned}
& h(t)=h_{0} \times\left(1-\frac{S_{\text {out }}}{S_{\text {tank }}} \sqrt{\frac{g t^{2}}{2 h_{0} \cdot(1+\zeta)}}\right)^{2}, \\
& \left.t(h)=\frac{S_{\text {tank }}}{S_{\text {out }}} \cdot \sqrt{\frac{2 h_{0}}{g} \cdot(1+\zeta) \times\left(1-\sqrt{\frac{h}{h_{0}}}\right.}\right)
\end{aligned}
$$

and each of these equations gives the same estimator

$$
\zeta[t, h(t)]=\left(\frac{S_{\text {out }}}{S_{\text {tank }}}\right)^{2} \frac{g t^{2}}{2 h_{0} \cdot\left(1-\sqrt{\frac{h(t)}{h_{0}}}\right)^{2}}-1,
$$

of the total HRC $\zeta$ of the facility pipeline from the experimentally measured time series of $h(t)$ or of the discharged volume $V(t)=S_{\text {tank }} \cdot\left(h_{0}-h(t)\right)$. The estimator (9) is valid when the time dependence of the calculated $\zeta \mathrm{s}$ is weak enough to fit acceptable systematic uncertainty of HRC measurements. 
In order to discriminate the $\zeta_{\mathrm{IC}}$ in question, two measurements are required, for the facility arrangements with and without IC. To substantiate this technique, let us distinguish local HRC $\zeta^{(I)}$ at joints of pipeline segments with different hydraulic sections and the specific friction loss coefficient $\zeta^{(f)}$ inside each of them. Let us note that such a diversification is inessential for the IC itself since its total $\zeta_{\mathrm{IC}}$ has to be measured.

Normalizing partial local $\zeta^{(1)}$ 's to the speed heads at the previous segment of a pipeline and $\zeta(f)$ s s of segments to their proper $\rho v^{2} / 2$ and assuming the additivity of dissipative pressure drops on successive segments of a pipeline (in $\mathrm{STH}$, this is a common approximation), for the experimental scheme with IC we obtain:

$$
\begin{aligned}
\zeta \frac{\rho v_{\text {in }}^{2}}{2} & =\zeta_{\text {tank }}^{(f)} \frac{\rho v_{\text {tank }}^{2}}{2}+\zeta_{\text {in }}^{(l)} \frac{\rho v_{\text {tank }}^{2}}{2}+\zeta_{\text {in }}^{(f)} \frac{\rho v_{\text {in }}^{2}}{2}+ \\
& +\zeta_{\text {IC }} \frac{\rho v_{\text {in }}^{2}}{2}+\zeta_{\text {out }}^{(f)} \frac{\rho v_{\text {out }}^{2}}{2}+\zeta_{\text {out }}^{(l)} \frac{\rho v_{\text {out }}^{2}}{2}
\end{aligned}
$$

or, taking into account mass conservation ratios (4),

$$
\zeta=\left(\zeta_{\text {tank }}^{(f)}+\zeta_{\text {in }}^{(l)}\right) \frac{S_{\text {in }}^{2}}{S_{\text {tank }}^{2}}+\zeta_{\text {in }}^{(f)}+\zeta_{\mathrm{IC}}+\left(\zeta_{\text {out }}^{(f)}+\zeta_{\text {out }}^{(l)}\right) \frac{S_{\text {in }}^{2}}{S_{\text {out }}^{2}} .
$$

Similarly, for the scheme without IC,

$$
\begin{gathered}
\zeta_{0} \frac{\rho v_{\text {in }}^{2}}{2}=\zeta_{\text {tank }}^{(f)} \frac{\rho v_{\text {tank }}^{2}}{2}+\zeta_{\text {in }}^{(l)} \frac{\rho v_{\text {tank }}^{2}}{2}+\zeta_{\text {in }}^{(f)} \frac{\rho v_{\text {in }}^{2}}{2}+ \\
+\zeta_{\text {in } / \text { out }}^{(l)} \frac{\rho v_{\text {in }}^{2}}{2}+\zeta_{\text {out }}^{(f)} \frac{\rho v_{\text {out }}^{2}}{2}+\zeta_{\text {out }}^{(l)} \frac{\rho v_{\text {out }}^{2}}{2} \\
\zeta_{0}=\left(\zeta_{\text {tank }}^{(f)}+\zeta_{\text {in }}^{(l)}\right) \frac{S_{\text {in }}^{2}}{S_{\text {tank }}^{2}}+\zeta_{\text {in }}^{(f)}+\zeta_{\frac{\text { in }}{\text { out }}}^{(l)}+\left(\zeta_{\text {out }}^{(f)}+\zeta_{\text {out }}^{(l)}\right) \frac{S_{\text {in }}^{2}}{S_{\text {out }}^{2}}
\end{gathered}
$$

The comparison of Eqs. (10) and (11) shows that $\zeta-\zeta_{0}=\zeta_{\text {IC }}-\zeta_{\frac{\text { in }}{\text { out }}}^{(l)}$. Since in our facility the hydraulic sections of the inlet tube and outlet valve are knowingly designed to have the same $\varnothing 32$ of the SCWCL piping, $\zeta_{\frac{\text { in }}{\text { out }}}^{(l)}<<\zeta_{\text {IC }}$ at their direct joint, and, finally,

$$
\zeta_{\mathrm{IC}}=\zeta-\zeta_{0} \text {. }
$$

Thus, we can directly measure the hydraulic resistance coefficient $\zeta_{\text {IC }}$ of the IC under the conditions of a measurement experiment at the Fig. 9 facility. This technique grants evaluation of $\zeta_{\text {IC }}$ for the IC internal fluent velocities of the range of relative width

$$
\frac{\Delta v_{\mathrm{IC}}}{v_{\mathrm{IC}}}=\sqrt{1-\frac{V_{\mathrm{tot}}}{S_{\text {tank }} h_{0}}}-1,
$$

where $V_{\text {tot }}$ is the total discharge of the Fig. 9 tank. This yields $\approx 20 \%$ uncertainty in speed, and, thus, in the velocity scaled Reynolds number. Accuracy can be improved by the increase of a tank diameter and the initial height of a water column. Besides, the characteristic dependence of flow energy turbulent dissipation is $\propto \operatorname{Re}^{-0.25}$. This effectively narrows the impact of the speed uncertainty to $\sim 6 \%$, which is fairly acceptable.

Repeating the measurement procedure for different thermodynamic conditions (e.g., at a different water temperature), one obtains $\zeta_{\text {IC }}$ for other Reynolds numbers due to the dependence of the density and viscosity of water on temperature [12]. Moreover, the results can be extrapolated to some preferable outer temperature/pressure conditions by means of the model dependent correlations of STH and classical hydrodynamics.
Again, we decompose the irradiation cell HRC onto local and frictional parts:

$$
\zeta_{\mathrm{IC}}=\zeta_{\mathrm{IC}}^{(l)}+\zeta_{\mathrm{IC}}^{(f)}
$$

The local part is due to the impact of the flow sharp narrowing/expansion at the IC joints with the main piping of the loop. In turbulent flows, it is practically independent on the range of flow velocities. The frictional part scales with the IC length $L_{\mathrm{IC}}$ and, following the DarcyWeisbach formalism, can be represented in the form:

$$
\zeta_{\mathrm{IC}}^{(f)}=\lambda \cdot \frac{L_{\mathrm{IC}}}{D_{\mathrm{IC}}} \cdot\left(\frac{S_{\mathrm{in}}}{S_{\mathrm{IC}}}\right)^{2},
$$

where $D_{\mathrm{IC}}$ is the IC effective hydraulic diameter, $\lambda$ is the Re-dependent coefficient of linear friction losses. The factor $\left(S_{\text {in }} / S_{\text {IC }}\right)^{2}$ emerges from $\zeta_{\text {IC }}$ normalization on the inlet speed head $\rho v_{\text {in }}^{2} / 2$ while friction losses are commonly normalized to the proper speed head of the IC.

For $\lambda$, we adopt the modified Altshoule correlation:

$$
\lambda=k_{\mathrm{IC}} \cdot 0.11 \cdot\left(\frac{\Delta}{D_{\mathrm{IC}}}+\frac{68}{\mathrm{Re}}\right)^{0.25},
$$

validated (at $k_{\mathrm{IC}}=1$, see ref. [13]) for round industrial steel piping with r.m.s. surface roughness $\Delta$. We introduced the shape factor $k_{\mathrm{IC}}$ to take into account the complex transversal geometry of the 4-channel IC design.

The hydraulic diameter $D_{\mathrm{IC}}$ was estimated as follows. For each channel, we measured the length averaged open area $S_{1}$ and the wettable perimeter $\Pi_{1}$ of inner surface and all the internals. To calculate the channel effective diameter $D_{1}$, the formula [13] $D_{1}=4 S_{1} / \Pi_{1}$ for non-circular channels was used. For parallel shunt connection of $N=4$ channels, we neglect differences of their loading and obtain $S_{\mathrm{IC}}=N \cdot S_{1}, \Pi_{\mathrm{IC}}=N \cdot \Pi_{1}$. The same formula $D_{\mathrm{IC}}=4 S_{\mathrm{IC}} / \Pi_{\mathrm{IC}}$ yields $D_{\mathrm{IC}}=D_{1}$.

Within the scope of the proposed extrapolation model, the searched dependence of the IC HRC on the Reynolds number is described by Eqs. (14) - (16) with three fitting parameters, the local HRC $\zeta_{\text {IC }}^{(l)}$, the shape factor $k_{\mathrm{C}}$, and the surface roughness $\Delta$ of the IC materials.

\subsection{EXPERIMENTAL DATA AND MEASUREMENT PROCESSING}

To implement the proposed technique for actual evaluation of the IC HRC Re-dependency, we measured the tank drainage timelines at various temperatures for three options of the measurement facility arrangement: (i) the reference one, without IC, (ii) assembled with the unloaded empty 4-channel IC, and (iii) assembled with the IC loaded with sample holding cassettes closely approaching the irradiation experiment loading plan.

For the IC relevant options, experiments were performed at two values of water temperature, room, $18^{\circ} \mathrm{C}$, and pre-boiling, $99^{\circ} \mathrm{C}$. By calculations, this yielded $\sim 3.5$ times large increase in Reynolds number Re.

The measurements without IC were carried out only at $18^{\circ} \mathrm{C}$. In this case, the friction effect is small compared with local losses when the stream enters from the tank into the pipe and exits the valve. Thus the temperature dependent viscosity impact is small and irrelevant.

For each option of the facility assemblage, three independent measurements were performed, each of them 
with filling of the tank up to the same water column level $h_{0}$. The tank drainage timeline measurements were performed until the same maximal discharge of $9 l$. The water level was fixed visually using a communicated vessels principle technique. The tank was linked with a vertical thin glass tube having $\approx 1 \mathrm{~mm}$ thick equidistantly plotted ticks. The value of division related to a 1 liter volumetric change of water in the tank.

The results were statistically averaged for each option along with proper estimation of experimental uncertainties of time series. Measurement errors of linear dimensions were adopted as $0.1 \mathrm{~mm}$ for the IC components and $1 \mathrm{~mm}$ for the rest of the facility except the variable diameter ball valve. For the latter one, the diameter uncertainty was calculated (at a valve drafts analysis) as a standard deviation from the reference $\varnothing 32$ along the open valve channel. This yielded the uncertainty of $4.4 \mathrm{~mm}$. For the roughness size of the IC internal surfaces, we adopted $\Delta=20 \mu \mathrm{m}$, a lower estimate for SS pipes without special treatment [13].

The process of tank drainage was digital camera recorded at $30 \mathrm{fps}$ ( $\approx 0.033 \mathrm{~s}$ time sampling). The instances $t_{l}$ $(I=0,1,2, \ldots 9)$ of each liter leakage were fixed after- wards at a per frame analysis of digital videos. The time series of a drained volume were reconstructed at an accuracy of $\approx 0.1 \mathrm{~s}$ per each liter taking into account the finite thickness of the communicating glass tube ticks.

The dependences of the tank discharge time on the escaped water volume for various options and conditions of the experiments with the IC are shown in Fig. 10. Curves depict the results of the non-linear least-square (LSq) fits of the measured data with the Eq. (8.2) model.

One can see that the developed model describes all the measured data and their observed trends well. The discharge time dependency is only weakly nonlinear. The time dependent drift of $\zeta$ (see Eq. (9)) is small and the obtained results of the LSq fit are well conditioned. The temperature effect is substantial only for the case of loaded IC due its highest hydraulic resistance.

Valuable input/output parameters of the experiment are summarized in Table 1. The tank discharge rate ranges from $0.5 \ldots 0.6 \mathrm{l} / \mathrm{s}$ (empty IC) down to $0.2 \ldots 0.25 \mathrm{l} / \mathrm{s}$ for the samples loaded one. It is much greater, $\approx 1.2 \mathrm{l} / \mathrm{s}$, in the reference case without IC and covers the entire range of mass flow rates $W=20 \ldots 80 \mathrm{gm} / \mathrm{s}$ expected at the SCWCL irradiation experiments.

Table 1

The parameters and results of the irradiation cell hydraulic resistance measurements

\begin{tabular}{|c|c|c|c|c|c|}
\hline Parameters & w/o IC & \multicolumn{2}{|c|}{ Empty IC } & \multicolumn{2}{|c|}{ Loaded IC } \\
\hline $\mathrm{T}$ & $18^{\circ} \mathrm{C}$ & $18^{\circ} \mathrm{C}$ & $99^{\circ} \mathrm{C}$ & $18^{\circ} \mathrm{C}$ & $99^{\circ} \mathrm{C}$ \\
\hline $\mathrm{D}_{\mathrm{IC}}(\mathrm{mm})$ & - & \multicolumn{2}{|c|}{$10 \pm 0.1$} & \multicolumn{2}{|c|}{$5.37 \pm 0.1$} \\
\hline $\mathrm{S}_{\mathrm{IC}}\left(\mathrm{mm}^{2}\right)$ & - & \multicolumn{2}{|c|}{$314 \pm 3$} & \multicolumn{2}{|c|}{$222 \pm 3$} \\
\hline$t_{9 L}(s)$ & $7.44 \pm 0.02$ & $16.32 \pm 0.09$ & $16.33 \pm 0.09$ & $40.24 \pm 0.02$ & $38.09 \pm 0.04$ \\
\hline $\mathrm{Q}$ (liter/s) & $1.21 \pm 0.02$ & $0.55 \pm 0.01$ & $0.55 \pm 0.01$ & $0.22 \pm 0.003$ & $0.24 \pm 0.003$ \\
\hline $\mathrm{v}(\mathrm{m} / \mathrm{s})^{\mathrm{s}}$ & $1.50 \pm 0.03$ & $0.69 \pm 0.02$ & $0.69 \pm 0.02$ & $0.28 \pm 0.006$ & $0.29 \pm 0.006$ \\
\hline $\mathrm{V}_{\mathrm{IC}}(\mathrm{m} / \mathrm{s})^{\mathrm{s}^{\mathrm{s}}}$ & - & $1.76 \pm 0.05$ & $1.75 \pm 0.05$ & $1.06 \pm 0.03$ & $1.12 \pm 0.03$ \\
\hline $\operatorname{Re} \times 10^{-3}$ ॐ中 & $46 \pm 1$ & $21 \pm 1$ & $74 \pm 3$ & $8.4 \pm 0.3$ & $32 \pm 1$ \\
\hline $\mathrm{Re}_{\mathrm{IC}} \times 10^{-3}$ 中出 & - & $17 \pm 1$ & $59 \pm 2$ & $5.1 \pm 0.2$ & $19 \pm 1$ \\
\hline$\zeta$ & $2.0 \pm 0.8$ & $27.3 \pm 1.0$ & $26.6 \pm 0.7$ & $168.0 \pm 2.8$ & $151.4 \pm 2.5$ \\
\hline$\zeta_{\mathrm{IC}}$ & - & $25.3 \pm 1.3$ & $24.6 \pm 1.3$ & $166.6 \pm 2.9$ & $149.4 \pm 2.7$ \\
\hline
\end{tabular}

The characteristic velocities are given for the facility inlet/outlet piping $(v)$ and inside the IC $\left(v_{\mathrm{IC}}\right)$.

ts The $v$ and $v_{\text {IC }}$ dependent Reynolds numbers fit the correspondent hydraulic diameters and temperature.

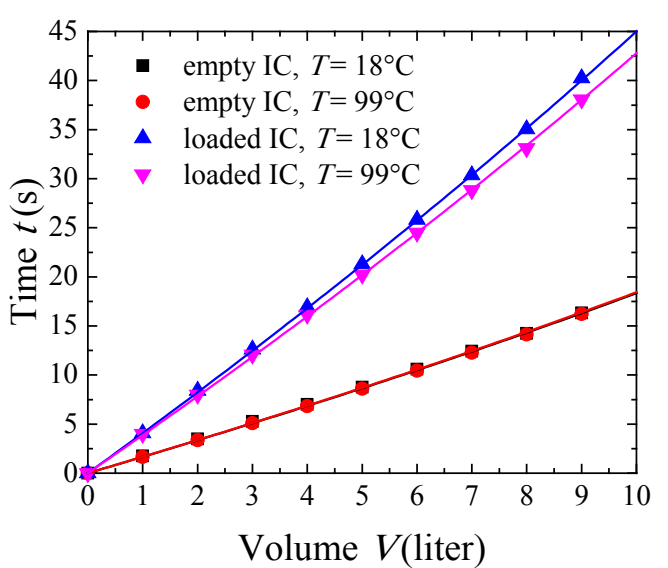

Fig. 10. The time series $t_{l}\left(V_{l}\right)$ of the tank discharge (markers) fitted with the Eqs. 8, 9 model (solid curves) for various IC loading options and water temperatures

In all cases, calculations of velocities and effective Reynolds numbers bear witness to the developed turbulence mode of a flow in the facility pipeline and IC.
As for the HRC values obtained, the strong effect of the IC presence ( $\zeta$ jumps from $\approx 2$ to $\approx 27$ ) and loading ( $\zeta_{\text {IC }}$ drastically increases to 166.6 at room temperature and to 149.4 at elevated $T=99^{\circ} \mathrm{C}$ ) is evident in the Table 1 data. One can see that $\zeta_{\text {IC }}$ of the loaded IC notably decreases with temperature due to lowering of water density and viscosity. Therefore, the extrapolation to the SCWCL experiment near-critical domain is expedient. This was done using the model (14) - (16). The results are presented in Table 2 and shown in Fig. 11.

Table 2

The best-fit values of the local HRC $\zeta_{\mathrm{IC}}^{(l)}$ and the shape factor $k_{\mathrm{IC}}$ cases of empty and loaded IC

\begin{tabular}{|c|c|c|}
\hline Parameters & Empty IC & Loaded IC \\
\hline$\zeta_{\mathrm{IC}}^{(l)}$ & $19.0 \pm 0.9$ & $77 \pm 19$ \\
\hline$k_{\mathrm{IC}}$ & 1 & $2.9 \pm 0.7$ \\
\hline
\end{tabular}

The evaluation of the Eqs. (14) - (16) parameters from the LSq fit of measured data shows that the IC local HRC is a substantial part of the total one, esp. for 
the unloaded IC $(\approx 19$ vs. $\approx 27$ of Table 1$)$. It was also found that the values of Table 2 substantially exceed the results of local HRC calculations (4.69 and 11.97 for empty and loaded IC, respectively) using the reference formulae [13] for a sum of those of the IC inlet flow sharp narrowing from $S_{\mathrm{in}}$ to $S_{\mathrm{IC}}$ and its expansion at the outlet. Hence, the IC 4-channel design essentially affects flow dynamics and hydraulic resistance. Indeed, this looks obvious when comparing the Fig. 2 picture with that of a round tube.

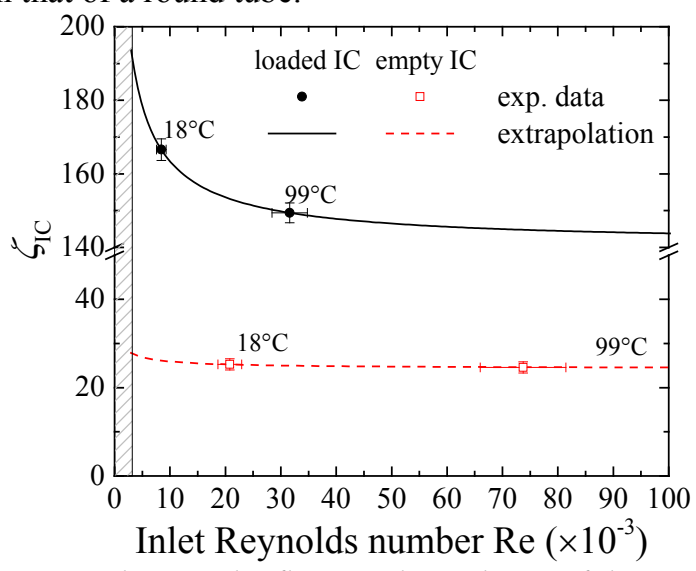

Fig. 11. The IC inlet flow Re dependence of the total HRC of the loaded (solid curve) and empty (dashed curve) irradiation cell. Markers depict (with uncertainties) the underlying experimental data

The main feature of the Fig. 11 recovered $\zeta_{\mathrm{IC}}(\mathrm{Re})$ dependencies is their weakness (within $<10 \%$ variation) in the highly turbulent domain $\left(\operatorname{Re}>>10^{4}\right)$ of the SCWCL operation. Therefore, our measurements are well-representative and informative. Finally, it is worth noting that at planned irradiation conditions $\left(T=360^{\circ} \mathrm{C}\right.$, $P=23.5 \mathrm{MPa})$ of the loaded IC the characteristic Re values of measurements correspond to the water coolant mass flow rates $W$ of 14 and $52 \mathrm{gm} / \mathrm{s}$ for 18 and $99^{\circ} \mathrm{C}$ measurements, respectively.

\subsection{COMPUTATIONAL FLUID DYNAMICS STUDY OF THE IRRADIATION CELL DESIGN}

To validate the developed design and the above discussed experimental scheme and the STH model, we also made an attempt to study the IC hydraulic resistance at the most adequate, hydrodynamic, rank using the FEM Computational Fluid Dynamics (CFD) code CFX. Though direct simulation of the measurement facility experiments is generally possible within the CFD framework, we found this too complex since a lot of experimental uncertainties had to be taken into account. The simplified technique was implemented.

The realistic 3D models of both empty and samplesloaded IC were developed as inputs of the CFD code. The steady state flow through them was FEM simulated at a series of inlet mass flow rates. The transversal section averaged pressure drop between the $\varnothing 32$ inlet and outlet piping segments was explicitly evaluated from the modeled fluid velocities field. Dissipative losses $\Delta P_{\text {loss }}$ were also extracted from the total ones. The HRC $\zeta_{\mathrm{IC}}$ was then estimated according to its definition (3).

The obtained results are mostly well interpreted qualitatively but also manifest certain quantitative discrepancies against the experimental data of Sec. 3.2.
At $18^{\circ} \mathrm{C}$, the CFD simulation results in $\zeta_{\text {IC }}$ of 22.9 (empty IC) and 114.2 (loaded IC). This yields $\approx 10$ and $\approx 50 \%$ high deviations off the Table 1 data. The former accuracy is reasonable while we consider the latter one as inadmissible. It requires further analysis.

In order to reveal the source of the observed deviations, we first compared the CFD and Eqs. (15), (16) evaluations of the frictional losses along the IC channels. We found them in good $(<10 \%)$ agreement: the Re dependent friction coefficient $\lambda$ is 0.032 (CFD) vs. 0.031 for empty IC and 0.130 (CFD) vs. 0.116 for the loaded one.

The comparative evaluation of local resistance factors leads to more complex and rather contradictory results. The Table 2 data manifest high $\zeta_{\text {IC }}^{(l)}$ sensitivity to the IC content (19 vs. 77) while the CFD simulation gives very close results $(\approx 14 \ldots 16)$ for both unloaded and loaded IC. It is within $20 \%$ for the simpler former case but is 5 times smaller for the most relevant latter one. One expects the local hydraulic resistance of the IC with loaded cassettes to be attributed to relatively large-scale low wave number turbulent twists of a fluid at periodically arranged deflectors (screws, notches) of sample holders. These effects are well observable but their contribution to the local HRC remains undervalued in the current CFD model. Its further refinement is underway.

However, we ventured to perform the CFD simulation of the coolant steady state flow through the loaded IC under the expected conditions of the irradiation experiment: $T=360^{\circ} \mathrm{C}, P=23.5 \mathrm{MPa}, W=50 \mathrm{gm} / \mathrm{s}$. The obtained results look very descriptive qualitatively and give an encouraging quantitative estimate.

A typical sketch of the coolant velocity $|\mathbf{v}|$ field is shown in Fig. 12. Its inhomogeneity and turbulent irregularity is obvious, inlet rebound, internal deflections and shadows as well as outlet vortices are evident.

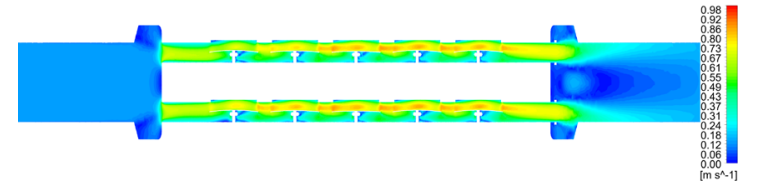

Fig. 12. The CFD-simulated coolant velocity field in the samples loaded IC in the vicinity of the supercritical transition. The coolant flows from left to right. For clarity, transverse dimensions in the figure are doubled

Moreover, on the outer, convex sides of the strained samples, the water velocity is 2-4 times higher than on their internal, concave side. This has to be taken into account at further post-irradiation analysis of possible effects of the Flow Accelerated Corrosion (FAC). Maximal velocities reach $\sim 1 \mathrm{~m} / \mathrm{s}$ which is close to those of the pilot SCWCL "Loop1a" irradiation experiment [3] and the characteristic coolant speed in a target SCWR.

The CFD calculated HRC was $\zeta_{\mathrm{IC}}=131$ under conditions of a near-critical domain. Finally, it is worth noting its much better $(\approx 14 \%)$ agreement with the experimentally measured, at $99^{\circ} \mathrm{C}, \zeta_{\mathrm{IC}}=149.4$.

\section{SYSTEM THERMAL HYDRAULICS CHARACTERIZATION OF THE PLANNED IRRADIATION EXPERIMENT}

In this section, we make use of all the data obtained for the STH parametric calculation of the planned irradiation experiments scenarios. The earlier developed 
[14] 1D STH model and code are used to predict the steady state mass flow rate $W$ and to profile the coolant temperature, density, and speed across the natural circulation loop. Calculations refer to the experimentally measured and properly extrapolated data of Fig. 11 on the hydraulic resistance of the irradiation cell loaded with strained samples. The base parametric space includes the horizontal heater power $Q_{\text {heater }}$ and the linac $e^{-}$-beam thermal power $Q_{\text {beam }}$ delivered to a coolant inside the IC. The mass flow rate sensitivity to the IC inlet temperature $T_{\text {in }}$ and the variations of $\zeta_{\text {IC }}$ are studied as well. The STH calculations results are presented in Figs. 13 to 16.

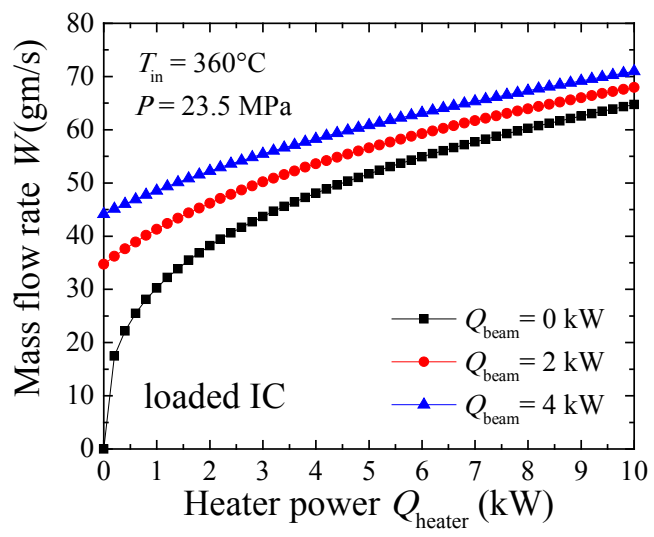

Fig. 13. The mass flow rate scenarios controlled by the horizontal heater power $Q_{\text {heater }}$ at different values

of the e-beam deposited thermal power $Q_{\text {beam }}$ incl. the beam-off case. The case $Q_{\text {beam }}=4 \mathrm{~kW}$ is most likely

The power consumption dependence of the mass flow rate (see Fig. 13) is weak. It roughly scales as $W \propto Q_{\text {total }}^{1 / 3}$. Assuming the 'Loop1a' irradiation [3] scenario $\left(Q_{\text {heater }} \approx 1 \mathrm{~kW}, Q_{\text {beam }} \approx 4 \mathrm{~kW}\right)$, we readily obtain $W \approx 50 \mathrm{gm} / \mathrm{s}$ for the strained samples filled IC. Greater $W=60 \ldots 80 \mathrm{gm} / \mathrm{s}$ were characteristic at previous irradiations [3] due to a larger open area and the hydraulic diameter of the "Loop1a" IC. The inevitable rate loss is caused by greater HRC of the novel IC, and is a cost of the capability to study corrosion under stress conditions.

This is described quantitatively by the Fig. 14 data. Though the $W\left(\zeta_{\mathrm{IC}}\right)$ dependency is also weak at large $\zeta_{\mathrm{IC}}$, the rate difference between the "Loop 1 b", $\zeta_{\mathrm{IC}} \approx 140$, and "Loop $1 \mathrm{a}$ ", $\zeta_{\mathrm{IC}} \approx 80$, is substantial at the same $T_{\text {in }}=360^{\circ} \mathrm{C}$.

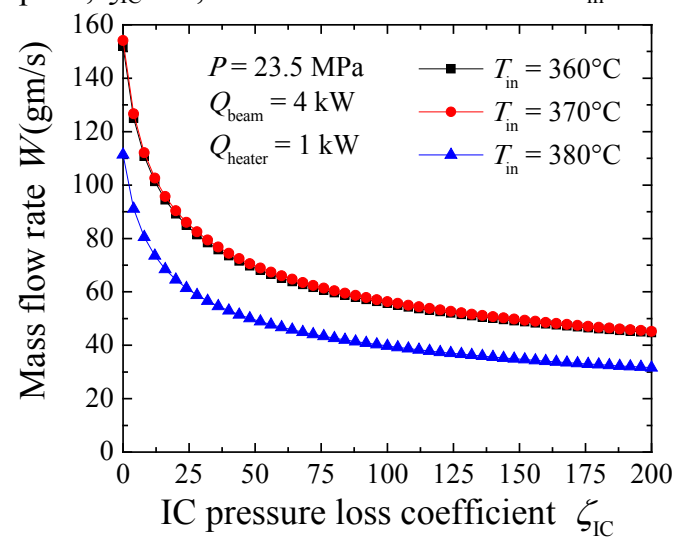

Fig. 14. The diagram of the mass flow rate sensitivity to the IC HRC $\zeta_{\mathrm{IC}}$ for the most probable power delivery scenario at both near-sub- $\left(T_{\mathrm{in}}=360 \ldots 370^{\circ} \mathrm{C}\right)$ and super-critical $\left(T_{\text {in }}=380^{\circ} \mathrm{C}\right)$ circulation regimes
Besides, one can note the mass flow rate drastic sensitivity to the IC inlet temperature in the vicinity of the pseudo-critical temperature $T_{\mathrm{pc}}(P)$ (see also Fig. 15) as well as at the facility overheat. The sharp decrease of $W$ is owing to the decrease of the water density at a supercritical transition, either pre-determined by an experiment schedule or occurring at an accidental heat sink loss similar to the NPP LOCA scenarios. They have to be prevented by means of careful control and emergency decrease of the linac beam power delivery.

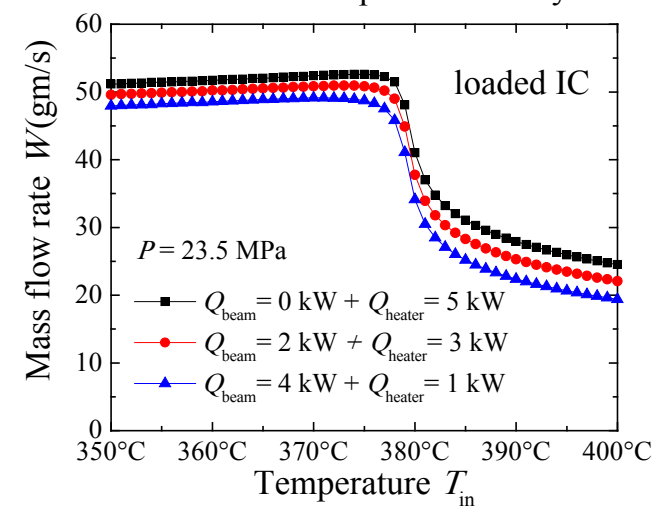

Fig. 15. Circulation scenarios as functions of the IC inlet temperature $T_{\text {in }}$ for different distributions of power deposition among the SCWCL heater and the linac e-beam at the same total power consumption of $5 \mathrm{~kW}$

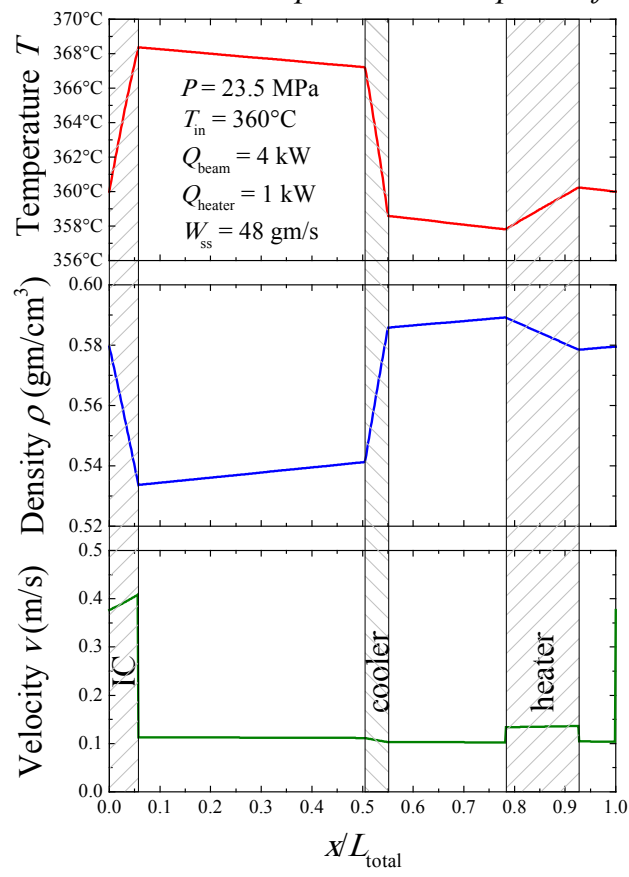

Fig. 16. Circumferential profiles of water temperature, density and linear velocity along the coolant path length

$x$ in the circulation loop at indicated conditions

The planned experiment circulation scenarios of Fig. 16 are self-descriptive. One can conclude that they confirm the applicability of the novel multi-channel irradiation cell design to the prospective experimental studies of the stress-assisted irradiation effects in corrosion and Stress Corrosion Cracking of the Generation IV SCWR structural steels and alloys.

\section{ACKNOWLEDGEMENTS}

This work was carried out at the expense of the budget program "Support for the Development of Priority Areas of Scientific Research" (КПКВК 6541230). 


\section{REFERENCES}

1. D. Guzonas, R. Novotny, S. Penttila, A. Toivonen, W. Zheng. Materials and Water Chemistry for Supercritical Water-Cooled Reactors // Woodhead Publ. Ser. in Energy, Elsevier UK Ltd. Cambridge. 2018, 264 p.

2. M.I. Ayzatsky, V.N. Boriskin, A.M. Dovbnya, et al. The NSC KIPT electron linacs - R\&D // Problems of Atomic Science and Technology. Series "Nuclear Physics Investigations”. 2003, № 2, p. 19-24.

3. A.S. Bakai, V.N. Boriskin, A.N. Dovbnya, S.V. Dyuldya, D. Guzonas. Supercritical Water Convection Loop for SCWR Materials Corrosion Tests under Electron Irradiation: First Results and Lessons Learned // Proc. of the $6^{\text {th }}$ Int. Symposium on SCWR's (ISSCWR-6), March 3-7, 2013, Shenzhen, Guangdong, China. Paper \#ISSCWR6-13062 (14 p.)

4. O.S. Bakai, V.M. Boriskin, A.M. Dovbnya, S.V. Dyuldya, D.A. Guzonas. Combined Effect of Irradiation, Temperature, and Water Coolant Flow on Corrosion of $\mathrm{Zr}-$, Ni-Cr, and Fe-Cr-based Alloys // Proc. of the ISSCWR-7, March 15-18, 2015, Helsinki, Finland. Paper \#ISSCWR7-2012 (14 p.); J. Nucl. Eng. Rad. Sci. 2016, v. 2, № 1, 021007 (11 p.)

5. A.S. Bakai, V.N. Boriskin, M.I. Bratchenko, Yu.V. Gorenko, A.N. Dovbnya, S.V. Dyuldya, G.G. Kovalev. Multi-Channel Cell to Irradiate the Material Specimens by Electrons in the Interior of the Supercritical Water Convection Loop // Problems of Atomic Science and Technology. Series "Nuclear Physics Investigations”. 2015, № 6, p. 130-136.

6. A.S. Bakai, E.Z. Biller, A.M. Bovda, et al. Monitoring the Flow Rate of Water in the Supercritical Convection Loop // Problems of Atomic Science and Technology. Series "Nuclear Physics Investigations”. 2016, № 3, p. 120-122.
7. A.S. Bakai, V.N. Boriskin, M.I. Bratchenko, et al. Regimes of Irradiation by Electrons of Samples of Materials in Supercritical Water Convection Loop // Problems of Atomic Science and Technology. Series "Nuclear Physics Investigations”. 2017, № 6, p. 185-190.

8. O.S. Bakai, V.M. Boriskin, M.I. Bratchenko, S.V. Dyuldya. e-Irradiation, Temperature, and Stress Effect on Corrosion of Zr-, Ni-Cr-, and Fe-Cr-based Alloys Near the Water Coolant Supercritical Transition // Proc of the $5^{\text {th }}$ Int. Conf. "High-Purity Materials: Production, Application, Properties”, Sept. 10-13, 2019, Kharkiv, Ukraine, p. 31-32.

9. G.X. Samigullin, V.A. Pystin. Eksperimentalnoe obosnovanie neobxodimosti ucheta napryazhennodeformirovannogo sostoyaniya metalla truboprovoda pri provedenii korrozionnogo monitoringa // Gornyj informacionno-analiticheskij byulleten. 2015, p. 176-182 (in Russian).

10. D.V. Vajnberg, E.D. Vajnberg. Raschet plastin. Kiev: "Budivelnik", 1970, 437 p.

11. F. Hecht. New Development in FreeFem++ // J. Numer. Math. 2012, v. 20, Nos. 3-4, p. 251-265.

12. W. Wagner et al. The IAPWS Formulation 1997 for the Thermodynamic Properties of Water and Steam // Trans. ASME. 2000, v. 122, p. 150-182.

13. A.S. Yurev i dr. Spravochnik po raschetam gidravlicheskix $i$ ventilyacionnyx sistem. Sankt-Peterburg: "Mir i semya", 2001, 1153 p. (in Russian).

14. S.V. Dyuldya, M.I. Bratchenko. Termogidravlicheskaya model svobodnoj konvekcii v sverhkriticheskoj petle stenda CU-EITF NNC XFTI. Trudy XX mezhd. konf. po fiz. rad. yavlenij i rad. Materialovedeniyu. NNC XFTI, 2012, p. 50-51 (in Russian).

\section{КАМЕРА ОБЛУЧЕНИЯ ЭЛЕКТРОНАМИ НАПРЯЖЁННЫХ СТАЛЬНЫХ ОБРАЗЦОВ В ПОТОКЕ СВЕРХКРИТИЧЕСКОЙ ВОДЫ ДЛЯ ИССЛЕДОВАНИЯ КОРРОЗИИ}

\section{А.С. Бакай, В.Н. Борискин, М.И. Брат ченко, Р.Н. Дронов, С.В. Дюльдя, Ю.В. Горенко, С.В. Шелепко}

С целью экспериментального изучения усиленной коррозии конструкционных материалов в потоке водного теплоносителя под облучением электронами разработана новая конструкция мишенной камеры. Описана схема приложения напряжений и рассчитано напряженно-деформированное состояние образцов. Гидравлическое сопротивление камеры с образцами из нержавеющей стали 12X18Н10Т было измерено на специальной установке и обсуждалось с точки зрения гидравлических и гидродинамических моделей. Термогидравлические расчеты продемонстрировали способность устройства эффективно функционировать в сверхкритической водной циркуляционной петле с естественной конвекцией.

\section{КАМЕРА ОПРОМІНЕННЯ ЕЛЕКТРОНАМИ НАПРУЖЕНИХ СТАЛЕВИХ ЗРАЗКІВ У ПОТОЦІ НАДКРИТИЧНОЇ ВОДИ ДЛЯ ДОСЛІДЖЕННЯ КОРОЗІЇ}

\section{О.С. Бакай, В.М. Борискін, М.І. Брат ченко, Р.М. Дронов, С.В. Дюльдя, Ю.В. Горенко, С.В. Шелепко}

3 метою експериментального вивчення посиленої корозії конструкційних матеріалів у потоці водного теплоносія під опроміненням електронами розроблена нова конструкція мішеневої камери. Описана схема прикладання напруги та розрахований пружно-деформований стан зразків. Гідравлічний опір камери зі зразками з нержавіючої сталі 12X18Н10Т був виміряний на спеціальній установці й обговорювався з точки зору гідравлічних та гідродинамічних моделей. Термогідравлічні розрахунки продемонстрували спроможність пристрою ефективно функціонувати в надкритичній водній циркуляційній петлі з природною конвекцією. 